EGU2020-5831

https://doi.org/10.5194/egusphere-egu2020-5831

EGU General Assembly 2020

(c) Author(s) 2020. This work is distributed under

the Creative Commons Attribution 4.0 License.

\title{
Below-ground functional traits during nutrient-acquisition affect the availability of rare earth elements to plants
}

\author{
Oliver Wiche ${ }^{1}$, Hermann Heilmeier ${ }^{1}$, and Olivier Pourret ${ }^{2}$ \\ ${ }^{1} \mathrm{TU}$ Bergakademie Freiberg, Institute for Biosciences, Biologie / Ecology Goup, Freiberg, Germany (oliver.wiche@ioez.tu- \\ freiberg.de) \\ ${ }^{2}$ UniLaSalle, AGHYLE, Beauvais, France
}

Rare Earth Elements (elements from 57 to 71; REEs) are present in almost all soils at quantities similar to some plant nutrients such as copper and zinc and, therefore, are of increasing interest in phytomining research. In soilREEs interact with nutrient-bearing soil phases (phosphates, Feoxyhydroxides, soil organic matter) which ultimately lowers their mobility in soil solution and availability to plants. The availability of nutrients in the rhizosphere (especially that of phosphorous) is dependent on the activity of rootsand associated microbes, particularly their ability to acidify the surrounding soil and release chelating compounds such as carboxylates. There is a general consensus that root exudates released under P/Fe deficiency (protons and chelating compounds) can mobilize REEs in soil. However, until today information on effects of below-ground functional traits in nutrient acquisition on the mobility of REEs in the rhizosphere and uptake in soil-grown plants is very scarce.Preliminary results from greenhouse and large-scale field experiments indicate that P-inefficient species show different REE-concentrations in their leaves than P-efficient species, and that the pattern of REEs is related to the composition of root exudates.These findings highlight the role of rhizosphere processes on the availability of REEs representing important background information for the optimization of phytoextraction techniques. Moreover, we hypothesize that concentrations and fractionation pattern of REEs in plant material could potentially be used as an "easily-measurable" tool to evaluate the nutrientacquisition strategy in plants. In ongoing experiments, this hypothesis will be rigorously tested by coupling a field sampling campaign of plant material from species with contrasting nutrientacquisition strategies along soils with changing nutrient availability (e.g. Western Australian chronosequences) as well as controlled greenhouse experiments for mechanistic elucidation of processes involved.

How to cite: Wiche, O., Heilmeier, H., and Pourret, O.: Below-ground functional traits during nutrient-acquisition affect the availability of rare earth elements to plants, EGU General Assembly 2020, Online, 4-8 May 2020, EGU2020-5831, https://doi.org/10.5194/egusphere-egu2020-5831, 2020 